\title{
Non-Verbal Teacher Training Program: Emotional Intelligence, Body Awareness and Communication
}

\author{
M. José Terrón-López, Rosa M. Rodríguez-Jiménez, Paloma J. Velasco-Quintana, \\ Ma del Mar Caja-López, Patricia Gracia-Parra \\ Universidad Europea de Madrid
}

\begin{abstract}
Nowadays higher education teachers are getting involved in motivating students to acquire significative learning throughout their life, as a contribution to their personal growth. To achieve this objective, specific teacher training in developing emotional competences in the teachers becomes necessary. The teacher, consciously or unconsciously, creates a work climate in the classrooms which affects to the learning outcomes. Though, students' motivation is affected by the teacher behavior, his proximity to the student, his ability to manage emotions, to empathize and to communicate effectively. Non-verbal aspects are undoubtedly relevant in this process. However, teachers receive non significative experiential training on somatic aspects concerning the presence and expression of the body in the classroom. This paper presents the preliminary results of implementing an experiential learning program focused on body awareness and non-verbal communication. This enactive learning allows to improve teaching competencies related to emotional intelligence (intra and interpersonal).
\end{abstract}

\section{Introduction}

Teachers thrive in an environment in which the intercommunication and creativity are essential both to ensure effective teaching and for the creation of employment structures which are healthy and productive. Emotional intelligence, understood as the ability to recognize one's own and others' feelings and the ability to use them $[1,2,3]$, developed in teachers becomes a fundamental aspect of their training [4]. The teacher, as a role model for learning, must have knowledge-based emotional selfawareness, self-regulation and self-motivation as Gardner [5] states in his analysis of multiple intelligences [6]. Thus, the benefits of this selfknowledge are perceived, not only in their teaching and their relationships with others but also in the skills development of their students. The teaching community mostly lacks specific training in body awareness that would allow them to use their communication skills in a most efficient way. Today skills-based teacher training [7, 8, 9] is carried out without including experienced work that addresses the importance of body awareness in the communicative process at inter and intra-personal levels. Hence, there exists a lack of recognition of the importance of integrating enactive learning skills [10] into teacher training. This is an important gap with direct implications on the degree of satisfaction with their communication skills at both teacher teacher and teacher - student levels. When we talk about enactive (in-action) learning we are referring to a type of experienced learning which is learned through conscious action [10]. Increased body awareness ensures greater internalization and control of the communicative phenomenon with direct impact on the classroom and on the relationship with students.

\section{Emotional Competences and body Awareness}

The methodological and paradigm changes in higher education, following the inception of the European Higher Education Area (EHEA) have resulted in new ways of communication between students and teachers. The university teacher must be able to innovate and create by searching for ways to develop the student skills required by a changing global society [9]. In this context, it is vital to give proper training for teachers so they would be able to teach according to these new parameters. It is a fact that 75 to 90 percent of the impact of a message is transmitted non-verbally [11] and therefore learning processes are more successful [12] when established in accurate non-verbal communication channels between teaching and learning agents. Research by Hamann and Mao [13] shows, for example, that pleasant looks activate our cortex gratification system, resulting in higher levels of motivation and involvement for a particular activity. Ambady and Rosenthal [14] pointed out that little samples of nonverbal language of secondary and higher education teachers determined the satisfaction levels of the students with these teachers. These results have been confirmed by other studies as Babab, Avni-Babad y Rosenthal ones [15]. They evaluated the nonverbal language of university teachers in different situations (first minute during the first lesson; giving lesson; speaking with students and tutorships in the teachers' office). Little samples of nonverbal language used by teachers correlated quite well with the items in the satisfaction questionnaire related to the expressive style of the teacher. 
According these authors, good teachers are expressive with hands, body, voice and faces. They keep on standing more than sitting, using all the available space. They are oriented to the audience. They show a good control managing all these factors to get the attention of the students. Nevertheless, they are relaxed and avoid showing aggressive attitudes.

Professional and personal skills development through movement and non-verbal language is not new $[16,11,13,12,17,6]$. For quite some time, the world's leading companies have integrated coaching programs that involve not only intellectual but also physical and emotional levels to promote efficient and productive healthy work environments [18]. In the United Kingdom and Belgium, groups, such as Boas and LifeDance, are coaching leaders on projects for companies. These projects include working with movement analysis and observation, and non-verbal language. Companies like Walt Disney Company, Heineken, Nokia, British Council, General Motors, IBM and many others have reaped the benefits of programs that incorporate the body and conscious experience as a tool for efficient and motivational transformation in competitive environments. In the United States companies like Limseonline, DynamicVoice or Move \& Change have spent years advising executives and companies using programs designed by therapists and educators specialized in Laban Movement Analysis [19], body therapies such as Dance Movement Therapy and techniques for Somatic Movement Education (SME). Specifically, this includes Body Mind Centering, Feldenkrais or Alexander techniques among others [20]. Furthermore, recent studies show that specific bodywork programs are particularly suitable for improving empathy in the workplace, thus impacting on and improving relationship skills, emotional intelligence, psychological well-being and life satisfaction [21, 22]. These improvements are a key to develop skills such as leadership, conflict resolution and relationships.

The latest research in neuroscience and the development of a set of disciplines under the name Somatic Movement Sciences (ISMETA) have supported, especially from the 70's on, the impact of an appropriate motor and bodywork development on the functioning of different brain functions [17, 23]. It has been found that changes in the repertoire of motor behavior produce changes both in cognitive and mental levels [24].

The incorporation of non-verbal and creative movement elements into the teaching - learning process has proven to be a powerful tool for the acquisition of general skills as it can be seen in previous research. In fact, authors such as Alles [25] incorporated in the literature other methods to acquire or to assess skills focused on professional development. Sternberg \& Williams [26] include in their works some implemented programs in education centers in the U.S. and Europe, which promote meaningful learning of a subject or specific skill through creative movement programs. In studies in the areas of Medicine and Psychology [27] proof of the advantages is that the creative movement and dance are for the general population, and specifically for the student population by supporting personal development, acquisition skill, and performance.

The experience described in this paper is justified based on all this. It is evident the interest of trying to improve intra and interpersonal teacher's competences (Emotional Intelligence, EI). We think that one of the ways of implementing would be by an experiential learning program focused on body awareness and non-verbal communication [28].

Teachers aware of their non-verbal behavior patterns can improve communication by attaining greater self-confidence and control on the impact of this communication on their work environment both outside and inside the classroom. Certain actions aimed towards this improvement have been developed, though there has not been any tracing or evaluation on how teachers who participated in these programs have evolved [29], and almost all of them took place in non-university environments. In this paper we intend to collect the perception of the teachers involved in this research Project using their reflexive diaries (done during the training program as we explain below).

\section{Methodology}

The work presented in this paper has been developed following the Action-Research (AR) methodology. Specifically the Kemmis model [30] because this methodology enhances teachers' understandings of their practices [31]. Using this methodology learning community teachers' are created which improve their teaching from the reflections done. This research design generates very dense description of everything that happens allowing a transfer of the results to other teaching communities. Following this methodology the phases set out were the following ones.

\subsection{Planning a change}

The action hypothesis was: could we improve the degree of Emotional Intelligence (EI) of our teachers? How could we improve their intra and inter personal competences? We considered that an answer could be implementing an experiential learning program focused on body awareness and non-verbal communication.

First, we invited those teachers interested in the body work program to participate in the sessions. A presentation meeting was held with the researchers and the participants' teachers. The group was formed 
by 22 volunteer teachers of different knowledge areas interested in improving their teaching by reflecting on communicative (mainly corporal) aspects.

Secondly, we designed a specific body work program oriented to the improvement of teachers' interpersonal competences. At this stage, we also established the movement sessions calendar as well as the researchers' meetings.

Finally we designed the collection data. We mainly used participant observation. Specifically, data was collected from the daily reflections of the participants on the program and from the researchers that were on the teachers' training sessions, from specific questionnaires and from the researcher's log. We also recorded, after each specific session, the comments made by the participants on the session final closure in order to be able to analyze them later on. We guaranteed at this stage the participants confidentiality.

After having designed this action plan, we started, with the participants, the acting and observing process.

\subsection{Acting and observing the process and consequences of the change}

Acting and observing was done in parallel. The proposal was implemented through 13 movement sessions. The movement sessions were done weekly in a wide room. Each session lasts for two hours. In parallel with these sessions, three meetings were kept between the researchers and the participants in the program in order to analyze the progresses done during the process.

\subsection{Reflecting on the process and consequences}

This phase was done in several stages. First the researchers collect the notes taken in the participants reflective diaries looking for evidences of:

- Comments related to explicit learning about acquired body awareness.

- Relevance of this knowledge in the intrapersonal level: has it helped me to know myself better? Have I acquired a bigger corporal self awareness?

- Relevance of this knowledge in the intra and inter-personal level: Do they help me to connect in a more conscious manner with my work environment?

- Other consequences of work; appearance of other reflections related to the work impact both at an intra- and inter- personal level, with negative or positive connotations for the teacher.
Then these comments and/or family units that were independent and recurrent were selected so that they were representative of teachers' reflections during an inductive process of categorization.

Data analysis was essentially qualitative: based on coding, classifying, presenting and validating the data by observing saturation in comments on the following:

- Evidence of acquisition of greater body awareness.

- Evidence of improvement in confidence and selfesteem.

- Evidence of the impact of the above on their skills and roles.

- Evidence of greater awareness of their practice in relation to inter and intra communicative skills.

- Evidence of changes in values and beliefs in relation to the body and its expressive potential.

- Evidence of changes in worldview (perception of the teacher on their relationship with the institution, education, the body and communication).

Enough saturation in the previous sections as well as future ones together with the researchers' notes would be useful to interpret the action impact.

Finally from the data analysis the actions undertaken will be revised. The researchers' group reflection permits to obtain results oriented to improve the actions to be implemented (re-planning phase).

\section{Bodywork program}

The bodywork program was designed from a wide perspective of techniques and approaches that are based on the body self-experience. The project is fed by two knowledge areas: the Dance Movement Therapy (DMT) and the Body Mind Centering (BMC). Both share the Enactive learning [10] as a key aspect. This implies that the bond between knowledge and movement is recognized; the knowledge emerges inevitably from the action in the world, and action is movement. Participants act from their own experience operating with the environment through the movement. The knowledge emerges from the experience. Therefore, the observation and the personal abilities modulation of introspection and interaction make them the true content of the sessions.

DMT suggests a holistic approach of life and human behavior. When it is put into practice on educational contexts, it provides an experiential frame for the teachers who, as reflective participants, will explore, observe and assess their own experience and teaching practice [24].

$\mathrm{BMC}$ provides a process of making questions to the body and its movement. Human experience can 
be observed, experimented, shared and investigated promoting presence-awareness and therefore the reorganization and changes of our behavioral patterns. We have worked following the BMC School funded in 1973 by Bonnie Bainbridge Cohen.

During the 13 sessions we intended to involve the teachers in their self-discovery, development of body awareness and exploration of the bonds between the personal experience and the personal practical knowledge, leading in a better and deeper knowledge of their communication abilities and skills in an educational context. DMT and BMC from an inactive knowledge, promote a learning process where teachers can harmonize emotional and cognitive aspects from their teaching practice. So, an acquisition of practical knowledge for their professional life is promoted.

\subsection{Movement program structure}

The program was structured in three main areas depending on the competences we wanted to develop. Ten of the 13 sessions were entirely dedicated to the body work and the other 3 were devoted to follow up and integrate the contents worked in the other ones.

Three work levels were organized as for developing competences:

- Level 1: intra-personal area. In the first three sessions the development of characteristic competences of this area was worked: selfconfidence, self-esteem and self-control.

- Level 2: inter-personal area. Without leaving the development of the previous level, the next three sessions were devoted to the development of communication abilities, empathy and decision making.

- Level 3: integration. The last four sessions were devoted to the development of observation and movement analysis abilities. The aim of these sessions was to facilitate tools to manage the observation of intra and inter personal processes. Laban Movement Analysis (LMA) was used. Laban's notation system for movement offers a valuable tool for describing movement patterns and providing the teachers a way to reflect about its application in their working environment.

The three following-up and integration sessions were done at the beginning (session 1), at the end of the Level 2 (session 8) and at the end of the Level 3 in order to finish the program (session 13). A special emphasis on the verbalization of the observation processes at the intra and inter personal dynamics was put, stimulating the participants to express their prospects and degree of satisfaction.

It is important to note that the participants didn't know the levels considered nor the competences distribution throughout them because we did not want to condition the participants in the reflections they did.

\subsection{Sessions Structure}

Work sessions had a similar structure during the entire program in order to make the participants familiar with the work routine promoting a balance between the individual and the group work and between verbal and non-verbal communication:

- Body warming

- Developing of dynamics to experience and deep about concrete aspects of corporality.

- Individual reflection.

- Closing circle. When finishing the session all the participants and the facilitator sit down in a circle in order to verbally share whatever they want during 15 minutes. These reflections are audio recorded and transcribed.

The movement sessions facilitators will also do a reflection after each session. The information that emerges from this phase contributes to structure and model the proposals and contents of the following sessions.

\section{Results}

All the teachers that have participated in the program have shown a high degree of satisfaction with it. In fact, only two teachers of the 22 that began the teacher training program have left it. This fact is a proof of the high degree of commitment of teachers involved in the experience. We present here the preliminary results of the program.

\subsection{Preliminary reflections}

In order to get a first idea of the "being" of the group, we ask the participants to fill out a questionnaire. This questionnaire had six open questions. The teacher was asked to reflect about their teaching and about the teachers they have had in the past, stressing on their non-verbal aspects of their communication. The idea was to detect which qualities should have a good teacher for them. After transcribing and analyzing the answers, the first categories that appeared from the codes gathered were three.

5.1.1. What the teacher knows category: the teacher as an expert on his subject or discipline. This category includes the following codes: life-long learning, experience and subject knowledge. Teachers enhance, as we expected, as good teachers qualities a teacher who has good subject knowledge 
and that enjoy teaching, though he studies in order to update himself.

5.1.2. What the teacher does category: educational competencies and teaching skills. This category includes codes related to pedagogic abilities. In this way they point out oral communication skills (verbal and nonverbal) as a key for a teacher. Other codes as innovation; participative; motivation; organized; fair/ courteous/firm; commitment; consistent; reflexive; flexible appear as well.

5.1.3. What the teacher is category: personal feature characteristics. This category includes the codes related with their being: emotions; nearness; patient; approachable; sincere; sense of humor/happy; social skills; enthusiasm. All these results match with other similar experiences found in the literature [9]. In those experiences, when they asked about the best teacher they remembered, all the participants pointed out mainly other aspects not really related with the knowledge of a subject or with its research trajectory, but with pedagogic skills or other personal characteristics. It is clear that, even though specific or technical knowledge is important ("what the teacher knows"), it isn't enough and the teacher has to develop as well other abilities that enhances the learning of the students ("what the teacher does") and that show them other skills from what "the teacher is".

\subsection{Preliminary results}

From the analysis of the reflections done by the participants after each session, we identify 4 main categories which describe the thoughts, the impressions, the worries and the teachers' observations related to the next aspects: intra- and interpersonal competences, bigger environmental perception, body awareness, and applicability of the knowledge emerged during the sessions to their classrooms.

\subsection{Intrapersonal competences development}

In this category we include the analysis of the reflections about how do teachers feel during the dynamics and how the session has influenced on their mood and energy levels.

From their comments we observe that the sessions produce a relaxation in the teachers whom start the sessions with a high degree of strain due to their daily routine and achieve to leave the sessions with a feeling of peace, well-being and optimism, "as always, I have arrived with strain and accelerated and I finish with a feeling of internal peace and an impressive quietness" [13/3/2012-11].
Teachers perceive their participation in the sessions as a personal benefit, "I really take this time as a present for me" [14/02/2012-2].

In them, they recognize the bond between the appearance and the emotional. This connection is reflected in comments as:

"during the session I established connections between the physical and the emotional, up to the point I could relax myself emotionally as I got relaxed physically" [14/02/2012-5]

"I feel that I connect my body and my mind getting to a harmony that allows me to follow up and finish the day enjoying it more" [13/3/2012-11].

Particularly one of the best valued moments of the sessions is the initial warming-up, as they understand it as a tool for relaxing and disconnect from the outside. This warm-up prepares the body and the mind for the following part of the session. In that sense we found the following comments done by the participants:

"I love the first part in which I think we get more conscious of ourselves, of our body, we disconnect of our daily life and problems and we start a relaxing phase that prepares ourselves emotionally for the rest of the activity" [21/02/12-M1].

"fantastic initial relaxation, a release of thoughts and body awareness are encouraged preparing the mind for the next exercises" [28/02/12-11].

We also have observed from their comments that teachers gradually add new vocabulary to describe their physical states.

"I've understood the different tonicity states. It is true that in my own experience some factors have carried me to the hyper relaxed state" [13/03/20124].

They considered that with the mirroring exercises they have learned a lot about themselves (selfknowledge).

This kind of dynamics is identified as useful for this objective, "today is the day I've learned more... about myself" [13/03/2012_M-3].

\subsection{Environment perception}

On the one hand, participant teachers have checked how the different states of tonicity affect the environment perception. On the other, the perception of the place that take up the own body and its position (when working with a dynamic entitled "I choose my place in the space"). "today's session has shown me how the whole body is a perceptive organ and how I am more sensitive to perceptions depending on my previous physical condition. There are conditions of bigger tension and alert and other more relaxed. When we are in a more stressed condition we lose more perceptive aspects while in a more relaxed condition we perceive more nuances" [28/02/2012_7]. The perception of the place that occupies our body is increased as well, "this course 
is helping me a lot to control my living space" [21/02/2012_M1]. The dynamic called "I choose my space" catches the teachers unaware. They find pleasant being conscious of the place they take up, "without any doubt the exercise I've liked more and the one which I felt more comfortable was the last one, locating our place in the space in silence. Moreover, apart from finding my own place and leaving my body, for instance, to hug the column when my mind was telling me not to do so, it seemed to me a beautiful exercise, plain of corporal beauty" [14/02/2012_M6].

\subsection{Interpersonal competences development: the body as an expression vehicle}

We collected in this category the reflections made about how the teachers make their relations with the others and how they integrate with the group. On the one hand we observed a bigger awareness of the ability of the body as an expression vehicle: "I have never planned before that we were able to talk to our body" [14/02/2012_4], "the possibility of knowing other colleagues only through the movement and the game results pleasant" [21/02/2012-11]. Particularly, we probe that the different state of tonicity influence on the communication ability. For instance, teachers said in their reflections that the extremes (hypertonic or hypotonic) are related to lack of communication as long as the neutral state to well-being, cordiality and keenness. Another thing to take into account is that after the program, teachers feel more comfortable with physical contact. "physical contact, to touch oneself, is so contained bearing with others, that, here is more and more natural, less unnatural. I think most of the people are getting more comfortable. I'm feeling better and I think that spontaneity is very rich, the improvisation that appears..." [21/02/2012_11].

\subsection{Teaching applicability}

We refer here how teachers have lived the program in order to benefit their teaching. Even though at the beginning they were quite skeptics about getting benefits on it ("the truth is that I don't know yet how we will apply what we do here to the teaching environment" [14/02/2012_M0]), once the program has gone on, positive reflections about the applicability in their teaching appear. On the one hand, analogies between what happens in the dynamics and in the classroom are established. Moreover, resources to be applied in the classroom are identified. In that sense one teacher states that "I have to say that all these sensations appear very often in my classrooms when for instance, all my attention is directed to a single student, or to a concrete gesture of a student, showing his disappointment. In that case, this sensation of stiffness appears and I lose my concentration easily, wanting to finish my class as soon as possible." [21/02/2012_M6]. Another comment found in that way is about his way of walking and, though, what he thinks he communicates to his students: "to the extent possible, I consider to correct mi own manner of walking. If I walk as if I were going to enter to a battle, I necessarily will communicate anxiety or even distance to the others (including my students, of course)" [13/03/2012_M3]. Teachers point out other resources that can be applied as the flexibility or adaptability: "the active adaptability to the group ... can be a useful tool to get an adequate management of a classroom. To learn to integrate oneself in a group without friction can facilitate the management of a group of students" [21/02/2012_8]. In particular, the session dedicated to how our feeling affects to the communication, and the simulation done about how to change the negative attitude of a student driving our own state has been remarked by the teachers. "it has been a very useful session for my teaching" [27/03/2012_M7].

"It seemed to me a very useful class for our daily teaching” [27/03/2012_8].

\section{Conclusions}

Teachers interested in improving significance learning in their students must look for new ways to do so. A specific teacher training program can help them. Moreover, emotional aspects should be included in order to promote satisfactory interpersonal relationships that improve the teaching learning process. When experiential enactive knowledge is incorporated, the teacher selfknowledge increase and therefore teachers are more aware of their expressive and communicative abilities. The training program we offered to the teachers was based on body work and non-verbal communication. The training was designed and taught by specialists in dance movement therapy and body mind centering.

In this paper, preliminary results of the teacher training program developed into an action research project show that the teachers declare a high degree of satisfaction with the initiative. In spite of the initial reticence (for most of the teachers this was the first experience to work with the own body in this creative way), sessions are perceived as a benefit in a personal and in a professional level. As the course is advancing, less reluctance is observed; teachers recognize the connection that exists between the appearance and the emotions, including in their vocabulary body aspects. Participants became aware of the non-verbal communication present in the classrooms and in their relations with partners. Therefore they began to include new resources in their teaching groups' management. 
A little learning community that wants to improve not only their "knowing" but also their "being" has been created.

We think that much work must be done in that sense in order to offer the teachers new teacher training programs to those that want to improve their degree of competences development.

Qualitative approach has pointed out the richness and variety in the way to integrate the training. In the next future we will incorporate mixed methodology. To incorporate quantitative measures can give us very interesting information to detect changes about self-knowledge, body awareness and empathy in teachers.

\section{References}

[1] D. Goleman, La inteligencia emocional, Barcelona: Kairós, 1996.

[2] E. Emmer, «Teacher emotions and classroom management,» de Annual Meeting of the American Educational Research, New Orleans, LA, 1994.

[3] A. Hargreaves, «Mixed emotions: teachers' perceptions of their interactions with students,» Teaching and Teacher Education, vol. 16, $n^{\circ}$ 8, pp. 811-826, 2000.

[4] R. E. Sutton y K. . F. Wheatley, «Teachers' Emotions and Teaching: A Review of the Literature and Directions for Future Research,» Educational Psychology Review, vol. $15, n^{\circ} 4$, pp. 327-358, 2003.

[5] H. Gardner, Inteligencias múltiples. La teoría en la práctica, Barcelona: Paidós, 1995.

[6] J. P. Guilford y R. Hoepfner, Analysis of Intelligence, New York: McGraw-Hill, 1971.

[7] S. Cassidy, «Developing employability skills: peer assessment in higher education,» Education and Training, vol. 48, no 7, pp. 508-517, 2006.

[8] M. J. García García, M. J. Terrón López y Y. Blanco Archilla, «Desarrollo de Recursos Docentes para la Evaluación de Competencias Genéricas,» ReVisión, vol. 3, n 3 3, pp. 17-37, Diciembre 2010.

[9] M. Á. Zabalza Beraza y M. A. Zabalza Cerdeiriña, Profesores y profesión docente. Entre el "ser" y el "estar", Madrid: Narcea, 2011.

[10] F. Varela, Conocer: Las Ciencias Cognitivas, tendencias y perspectivas, Barcelona: Gedisa Editorial, 1988.

[11] C. M. Galloway, «Nonverbal: Authentic or Artificial,» Theory into Practice, vol. 16, n 3, pp. 129-133, June 1977.

[12] S. Erk, M. Kiefer, J. Grothe, A. P. Wunderlich, M. Spitzer y H. Walter, «Emotional context modulates subsequent memory effect,» NeuroImage, vol. 18, n², pp. 439-447, February 2003.

[13] S. Hamann y H. Mao, «Positive and negative emotional verbal stimuli elicit activity in the left amygdala,» Neuroreport, vol. 13, $\mathrm{n}^{\mathrm{o}}$ 1, pp. 15-19, 21 January 2002.

[14] N. Ambady y R. Rosenthal, «Half a minute: predicting teacher evaluations from thins slices of behavior and physical attractiveness,» Journal of Personality and Social Psychology, vol. 64, nº 3, pp. 431-441, 1993.

[15] E. Babad, D. Avni-Babad y R. Rosenthal, «Prediction of Students' Evaluations from Brief Instances of Professors' Nonverbal Behavior in Defined Instructional Situations,» Social Psychology of Education, vol. 7, $\mathrm{n}^{\circ} 1$, pp. 3-33, 2004

[16] R. Boyatzis, A. Mckee y F. Johnston, Líder emocional, Barcelona: Ediciones Deusto, 2008.

[17] G. Rizzolatti y C. Sinigaglia, Las neuronas espejo. Los mecanismos de la empatía emocional, Barcelona: Paidós, 2006

[18] S. Boas, "Via тм Coaching; an introduction to business leaders," 2009. [Online]. Available: http://www.boastl.com/downloads/boas\%20via\%20c oaching $\% 20 \% 20$ an $\% 20$ introduction $\% 20$ for $\% 20$ managers. pdf. [Accessed 15 january 2011].

[19] S. Thornton, Laban's theory of movement: A new perspective, Plays, 1971.

[20] J. Fast, El lenguaje del cuerpo, Barcelona: Kairós, 1971.

[21] D. Fischman, La mejora de la capacidad empática en profesionales de la salud y la educación a través de talleres de Danza Movimiento Terapia, Palermo: Universidad de Palermo, 2005.

[22] D. L. Fraenkel, «The Relationship of Empathy in Movement to Synchrony, Echoing, and Empathy in Verbal Interactions,» American Journal of Dance Therapy, vol. 6, $\mathrm{n}^{\mathrm{o}} 1$, pp. 31-48, 1983.

[23] V. S. Ramachandran, Los laberintos del cerebro, Barcelona: La liebre de marzo, 2008.

[24] H. Payne, Creative Movement and Dance in Groupwork (Creative Activities in Groupwork), Speechmark Publishing Ltd, 1997.

[25] M. A. Alles, Gestión por competencias. El diccionario, Granica, 2005.

[26] R. J. Sternberg y W. M. Williams, Educational Psychology, Pearson Higher Education, 2010.

[27] A. L. Fuentes Serrano, "El valor pedagógico de la danza," 03 april 2006. [Online]. Available: http://hdl.handle.net/10803/9711. [Accessed 30 july 2012]. 
[28] K. Bat-Sheva, «A concept of "Body Knowledge" and an evolving model of "Movement Experience": Implications and application for curriculum and teacher education,» American Journal of Dance Therapy, pp. 2148, 1994.

[29] H. Álvarez de Arcaya Ajuria, «Influencias de la comunicación no verbal en los estilos de enseñanza y en los estilos de aprendizaje,» Revista de Educación, no 334, pp. 21-32, 2004.

[30] S. Kemmis y R. Mctaggart, Cómo planificar la investigación-acción, Barcelona: Laertes, 1988.

[31] J. Elliot, La investigación-acción en educación, Madrid: Morata, 2000. 